\title{
Modeling of Homogeneous Charge Compression Ignition (HCCI) of Methane
}

\author{
J. R. Smith \\ S. M. Aceves \\ C. Westbrook \\ W. Pitz
}

This paper was prepared for submittal to the ASME Internal Combustion Engine 1997 Fall Conference

Madison, Wisconsin

September 27-October 1, 1997

May 6, 1997

This is a preprint of a paper intended for publication in a journal or proceedings. Since changes may be made before publication, this preprint is made available with the understanding that it will not be cited or reproduced without the permission of the author. 


\section{DISCLAIMER}

This document was prepared as an account of work sponsored by an agency of the United States Government. Neither the United States Government nor the University of California nor any of their employees, makes any warranty, express or implied, or assumes any legal liability or responsibility for the accuracy, completeness, or usefulness of any information, apparatus, product, or process

disclosed, or represents that its use would not infringe privately owned rights. Reference herein to any specific commercial product, process, or service by trade name, trademark, manufacturer, or otherwise, does not necessarily constitute or imply its endorsement, recommendation, or favoring by the United States Government or the University of California. The views and opinions of authors expressed herein do not necessarily state or reflect those of the United States Government or the University of California, and shall not be used for advertising or product endorsement purposes. 


\title{
MODELING OF HOMOGENEOUS CHARGE COMPRESSION IGNITION (HCCI) OF METHANE
}

\author{
J. Ray Smith, Salvador M. Aceves, Charles Westbrook and William Pitz \\ Lawrence Livermore National Laboratory \\ Livermore, CA 94551
}

\begin{abstract}
The operation of piston engines on a compression ignition cycle using a lean, homogeneous charge has many potential attractive features. These include the potential for extremely low $\mathrm{NO}_{\mathrm{x}}$ and particulate emissions while maintaining high thermal efficiency and not requiring the expensive high pressure injection system of the typical modern diesel engine. Using the HCT chemical kinetics code to simulate autoignition of methane-air mixtures, we have explored the ignition timing, burn duration, $\mathrm{NO}_{\mathrm{x}}$ production, indicated efficiency and power output of an engine with a compression ratio of 15:1 at 1200 and $2400 \mathrm{rpm}$. HCT was modified to include the effects of heat transfer. This study used a single control volume reaction zone that varies as a function of crank angle. The ignition process is controlled by varying the intake equivalence ratio and varying the residual gas trapping (RGT). RGT is internal exhaust gas recirculation which recycles both heat and combustion product species. It is accomplished by varying the timing of the exhaust valve closure. Inlet manifold temperature was held constant at 330 Kelvins. Results show that there is a narrow range of operational conditions that show promise of achieving the control necessary to vary power output while keeping indicated efficiency above $50 \%$ and $\mathrm{NO}_{\mathrm{x}}$ levels below $100 \mathrm{ppm}$.
\end{abstract}

Nomenclature

BDC - bottom dead center

CAD - crank angle degrees

DI - direct injected

EGR - exhaust gas recirculation

RGT - residual gas trapping (in-cylinder EGR)

RON - research octane number

TDC - top dead center

\section{INTRODUCTION}

The concept of homogeneous charge compression ignition (HCCI) has been described before by a number of researchers. Onishi, et al. [1979] experimentally studied homogeneous charge compression ignition in a two-stroke engine and achieved low cyclic variation at idle and up to $40 \%$ load. Najt and Foster [1983] used a simplified kinetics scheme to correlate heat release in a Waukesha Cooperative Fuels Research (CFR) engine with modest compression ratios and high EGR. Thring [1989] used a Labeco Cooperative Lubricant Research (CLR) engine with a wedge shaped combustion chamber at 8:1 compression ratio with external mixture preparation and heating of a gasoline mixture above $640 \mathrm{~K}$ and EGR rates of 13 to $33 \%$ to map out permissible operating parameters. Thring also coined the most descriptive name of this combustion process HCCI which these authors will use in this work. Ryan and Callahan [1996] used a variable compression ratio engine to map operational space for HCCI using 47 cetane diesel fuel. They found that compression ratio, EGR rate and equivalence ratio were adequate for control. Nakagome, et al. [1997] used early injection of diesel fuel in a DI Diesel to achieve HCCI resulting in very low $\mathrm{NO}_{\mathrm{x}}(20 \mathrm{ppm})$. In some preliminary work to the current study [Smith 
and Aceves, 1996] used the HCT code to simulate methane HCCI combustion without heat transfer losses over a range of compression ratios of 10:1 to 40:1 and manifold pressures from 0.5 to 2 atmospheres. That study employed heated inlet temperatures up to $500 \mathrm{~K}$ and EGR rates up to $30 \%$. In all of these studies control of the start of ignition and high heat release rate are the primary issues.

In the ideal Diesel cycle, heat is added to the working fluid at constant pressure. This is approximated in real diesels by the injection of a high cetane fuel spray into the compressed air mass where autoignition occurs. Ignition delay after the start of injection is controlled by the cetane number of the fuel. The rate of heat release is controlled by the rate at which fuel is injected and the rate at which fuel vaporization and mixing occur. $\mathrm{NO}_{\mathrm{X}}$ production is inherently high in Diesels because of the high temperatures in the combustion regions where the mixing brings about near stoichiometric conditions which produces high temperatures. Engine power is controlled by the quantity of fuel injected.

In the ideal Otto cycle, heat is added to the working fluid at constant volume. This process is approximated by igniting a premixed high octane fuel and air mixture. The fuel air mixing is accomplished either before the mixture is introduced into the cylinder by carburetion or more recently by inlet port injection of the fuel into the air flow. The fuel air mixture is usually assumed to be homogeneous. Ignition is initiated by a spark plug. The heat release rate is controlled by flame propagation from the spark gap through the mixture at a rate that is dependent primarily on the turbulent mixing of the hot products behind the flame front with the unburned mixture ahead of the flame front. $\mathrm{NO}_{\mathrm{X}}$ formation is high if stoichiometric mixtures are used, but three-way catalysts are currently used to reduce the $\mathrm{NO}_{\mathrm{X}}$ to low levels. The HCCI combustion process uses the same autoignition process as a Diesel but results in rapid heat release and therefore better approximates an Otto cycle than a Diesel cycle.

\section{PROPOSED HCCI CONCEPT}

Our concept of HCCI is to use compression ignition of a homogeneous charge mixture prepared in the manifold of a very high octane (and low cetane) fuel at very lean conditions. This is contrasted to earlier work [Thring, 1989] where a 87 octane fuel was used at 8:1 compression ratio or the early direct injection studies [Nalagome, et al., 1997] at 16.5:1 compression ratio using a 62 cetane fuel. In our current study we have chosen methane as the fuel with its $120 \mathrm{RON}$. Ignition is by autoignition thus relatively high compression ratios will be needed. Because the mixture is homogeneous and lean, no particulates will be formed. Thermal efficiency in an HCCI engine is likely to closely approach that of the standard diesel as was demonstrated by Thring.

The HCCI process gives up two important control aspects: 1) the timing of the start of ignition is not directly controlled by any external event such as the beginning of injection in the standard Diesel or the sparking of the spark plug in the Otto cycle engine, and 2) the heat release rate is not controlled by either the rate and duration of the fuel injection process as in the standard Diesel or by the finite turbulent flame propagation time in the Otto cycle engine. There are a number of possible solutions to these two problems thanks to recent advances in modern engine technology. Before discussing potential control strategies for starting ignition and heat release rate, let us assume that a pressure transducer will be fitted to the combustion chamber. The pressure signal along with suitable electronics gives the crankangle of the start of combustion, the duration of combustion and when peak pressure occurs. Secondly, let us assume that a spark plug or glow plug is included in the cylinder head to start the first few cycles of engine operation. Such an ignition source may be required if operation outside the HCCI operational regime of parameters is desired. 
Autoignition of a homogeneous charge is virtually identical to the knock process that can occur in the Otto cycle engine. From detailed kinetic modeling of motored engines using a homogeneous charge of a variety of fuels, it is known that the controlling parameters in the initiation of this process are the fuel components (mixtures behave differently than neat fuels), and the temperature and density history that the fuel air mixture experiences. Motored engine experiments at General Motors Research Laboratories [Curran et al., 1995] agree well with HCT simulation of this process. Thus if the precise conditions at the start of compression are known (species, temperature and density) the beginning of combustion can be accurately predicted. Control of the start of ignition external to the combustion chamber can be accomplished by 1) changing the equivalence ratio of the mixture; 2) changing the species using RGT; 3) changing the initial temperature of the charge; or 4) changing the initial density of the charge. For example, if the pressure information indicates that the previous combustion cycle occurred later than the ideal timing for maximum efficiency, the mixture equivalence ratio can be increased for the next cycle. Note that this only requires a fast response time, low pressure injection system similar to that used in today's port injection gasoline engines. Or alternatively, if electromagnetic intake and exhaust valves are used [Theobald and Henry, 1994], the exhaust valve can be opened late to increase in-cylinder EGR and initial temperature for the next cycle.

Calculations show that variations in the exhaust valve timing can be used to change the charge temperature at BDC by several hundred Kelvins due to changes in the amount of trapped hot residual gases kept in the cylinder for the next cycle. An electromagnetic intake valve timing can also be used to vary the initial charge density without suffering throttling losses. Through detailed kinetic modeling, the conditions required to control the initiation of autoignition can be predicted. The calculation of the required changes to keep the combustion starting at the proper time could be used to generate a look up table for the engine controller thus avoiding any real time detailed calculations.

As an alternative to the above ignition control strategies proposed, it is also possible to raise the temperature and the density of the charge by firing a spark plug and start a flame propagating that will further compress the unburned mixture. This would be a very slow flame in the lean, low turbulence mixture and would not have time to propagate across the chamber before conditions in the unburned gases reached the autoignition point. This type of operation, if required, would in effect be an Otto cycle engine process with "soft knock" due to the very lean operation. Yet another ignition alternative is to direct inject either near TDC or at the intake valve a small amount of high cetane fuel to promote earlier autoignition. Injection near TDC would be the equivalent to pilot injection diesel operation which has been used in some diesel dual fuel operation on natural gas [Jensen, 1994]. Neither of these alternatives are as desirable due to cost and complexity, but they do exist as backups if the preferred control is too sensitive to be a robust control strategy. This paper explores only the use of externally prepared equivalence ratio and RGT as controls.

\section{COMPUTATIONAL MODEL}

All of the modeling computations in this study were carried out using the HCT model [Lund, 1978]. This model has been used in a large number of investigations over the past years, and in particular was used in our past studies of engine knock and autoignition [Westbrook, et al., 1991; Pitz, et al., 1991, Westbrook, et al., 1988]. The HCT code permits the use of a variety of boundary and initial conditions for reactive systems, depending on the needs of the particular system being examined. In the present case, the relevant conditions are those which describe the bulk gases in the combustion chamber.

During an engine cycle, a number of processes occur which influence the time variation of the temperature and pressure of the bulk reactive gases in the combustion chamber. Piston 
motion first compresses and heats the bulk gases and then expands and cools them. During this time chemical reactions release heat and change the overall composition of the gases. Fresh unreacted fuel and air are added to hot residual gases left over from the previous cycle. Residual gases from the previous engine cycles which consist largely of water vapor, $\mathrm{CO}_{2}$ and molecular nitrogen and oxygen are assumed fully mixed with the fresh charge. The mixed temperature is estimated by a published procedure [Heywood, 1988]. Equivalence ratio is defined as that of the incoming mixture in the manifold - not the mixture in the cylinder which can be leaner due to residual oxygen. In addition, heat losses to the engine chamber walls, blowby, fuel trapping in crevice volumes, and other processes occur. Of these, in the current simulations, only heat transfer losses are accounted for.

The computational model treats the combustion chamber as a homogeneous reactor with a variable volume. The volume is changed with time using a slider-crank formula as described by Heywood [1988] and used in previous modeling studies [Westbrook, et al.,1991; Green, et al., 1987]. The formula uses engine speed, compression ratio, piston geometry and stroke to convert absolute time into crank angle position. The heat transfer submodel that we employed in the HCT code simulations uses Woschni's correlation [Woschni, 1967].

The present model ignores spatial variations in the combustion chamber, treating heat loss as a distributed heat transfer rate, proportional to the temperature difference between the average gas temperature and a time-averaged wall temperature. In this study the wall temperature was assumed to be $600 \mathrm{~K}$. The authors recognize that this is a great oversimplification of the actual condition within the combustion chamber. In particular, the boundary layer which contains significant mass must be at a lower temperature that the bulk gas near TDC. Due to the extreme temperature history sensitivity of the autoignition and heat release processes, our estimates of burn duration will be shorter than in experiments. That is, the boundary layer will always burn last and extend the heat release rate compared to this simulation.

Each simulation is started at BDC with the equivalence ratio of the intake charge at $330 \mathrm{~K}$ added to the variable (fraction of total charge and residual temperature) residual gas fraction at their mixed mean temperature and one atmosphere pressure. The chemical reactions are computed explicitly in the kinetics model. Thermodynamic table values of $c_{p}$ and $c_{v}$ are explicitly calculated to account for enthalpy and pressure changes. The simulation is stopped at BDC and the indicated efficiency is computed. The NO values reported are those at BDC. The chemical kinetic reaction mechanisms used by the model for methane ignition and NO production have been extremely well established and are widely used. The chemical kinetic mechanism for methane was taken from Curran et al. (1995). The mechaism for nitrogen kinetics is from the Gas Research Institute mechanism version 1.2 (Frenklach, et al., 1995).

\section{ENGINE DESCRIPTION}

The engine is assumed to have a bore and stroke of $100 \mathrm{~mm}$ and a connecting rod length of $160 \mathrm{~mm}$. The compression ratio is $15: 1$ and the displacement per cylinder is 0.785 liter. The engine is assumed to have variable valve timing for the exhaust so as to allow quick changes in the RGT. This arrangement allows near adiabatic EGR which means that the charge temperature rises with RGT fraction. The engine is assumed to be unthrottled at all operation points with a volumetric efficiency of $100 \%$ for both engine speeds simulated.

\section{RESULTS}


By making over one hundred simulation runs we have mapped the regions of acceptable operation in the HCCI mode. The results for $1200 \mathrm{rpm}$ are shown in Figure 1 in equivalence ratio versus RGT fraction parameter space. The lower left of the plot shows the region where only partial burn takes place. The boundary between partial burn and complete burn was found to be extremely sharp. The crescent region diagonally across the center of the plot represents the region where the acceptable operation both in terms of ignition timing and burn duration can be expected. Above this region is an area that yields extremely short heat release of less than 5 CAD. At center right is a region where the autoignition process takes place so early in the cycle that significant negative work is done on the piston, i.e., earlier than $20 \mathrm{CAD}$ before TDC. Although the plots are carried out to 0.9 RGT, the practical limit may not be much greater than 0.7 due to power requirements to overcome engine friction.

Figure 2 displays the start of ignition as defined by one percent of the fuel being consumed for the same $1200 \mathrm{rpm}$ case. The -20 CAD ignition timing forms the boundary of the right side of the acceptable operation region. The ignition timing is a relatively smooth curve as a function of the equivalence ratio and the RGT fraction. Figure 3 gives insight as to why this is true. It shows the temperature at BDC that the fresh charge and the trapped residual gas mix to. These BDC temperature curves closely parallel the ignition timing curves of Figure 2.

The $1 \%$ to $99 \%$ burn duration is shown in Figure 4. All burn durations are noticeably short. We have included burn durations down to 5 CAD in the acceptable region which may be overly optimistic. Recall, however, that the single zone model used in the current simulations will, almost certainly, under predict the actual burn duration. Desirable burn durations are compressed to the left side of the acceptable operation region precariously close to the partial burn region. Operation here will represent a challenge to modern engine control engineering. We note that although the same trends are seen in the shape of the burn duration curves as the ignition curves there is less change at high RGT fractions. No direct method was found in this study to control the rate of heat release. However, it does appear possible to stay in the 10 to $20 \mathrm{CAD}$ burn duration region using the intake equivalence and exhaust valve timing.

The indicated efficiency is shown in Figure 5. A large region over 50\% efficiency lies within the acceptable operation region. This area of high efficiency is at low power levels and potentially has much higher efficiency than spark-ignited engines due primarily to the lack of throttling losses and perhaps even higher than diesels due to shorter heat release rates.

The NO emissions were found to be more than $98 \%$ of the total NOx emission. They are plotted in Figure 6. As expected when the equivalence ratio rises above 0.5, NO emissions rises quickly. If limited to less than 0.5 equivalence ratio, this engine would have poor power output per displacement. However, one control strategy could be to avoid intermediate equivalence ratios between 0.5 and stoichiometric, go directly to stoichiometric for high power output and include a three-way catalyst to reduce NO to acceptable levels.

As engine speed is increased the heat transfer losses are reduced but there is less time for reactions to occur and ignition happens a bit later. Thus Figure 7 indicates a very similar shaped region of acceptable operation at $2400 \mathrm{rpm}$ compared to $1200 \mathrm{rpm}$. Although the best region of operation is shifted to slightly higher RGT fractions at $2400 \mathrm{rpm}$, the burn duration contours in CAD remain nearly the same as for $1200 \mathrm{rpm}$. All of the detail comments on Figures 1 through 6 apply to this higher speed. 
As shown in Figure 8, at $2400 \mathrm{rpm}$ the NO production is reduced at very lean operation due to kinetic rate limited reactions. However, significantly higher NO is produced in the 0.9 equivalence ratio area due to the higher temperatures achieved with the reduced heat loss. Specific power NO emissions are plotted in Figure 9 for the two engine speeds. The peak for each speed occurs at 0.9 equivalence ratio and the end of the each curve is at stoichiometric.

Finally, the indicated efficiency for HCCI operation along the 20 CAD burn duration contours are plotted in Figure 10. The uniformity of the high efficiency as the power for a single cylinder is changed is very encouraging.

\section{CONCLUSIONS}

* Based on these HCT simulations there appears to be a region of acceptable engine operation using methane to achieve the HCCI combustion process.

* High indicated efficiency at low power levels should be achievable.

* NO emission levels of less than 100 ppm can be achieved without a catalyst at equivalence ratios less than 0.5 .

* Equivalence ratio and residual gas trapping (RGT) are likely to be adequate controls if direct pressure feedback information is used reduce cycle-to-cycle variation.

\section{ACKNOWLEDGMENT}

The authors gratefully acknowledge the support and encouragement of the Program Managers Gurpreet Singh and William Siegel in doing this research. The authors thank Henry Curran of LLNL for supplying the chemical mechanism.

\section{REFERENCES}

Curran, J. Henry, Gaffuri, Paolo, Pitz, William J., Westbrook, Charles K., and Leppard, William R., 1995, "Autoignition Chemistry of the Hexane Isomers: An Experimental and Kinetic Modeling Study,”SAE paper 952406.

Frenklach, M.,Wang, H., Goldenberg, M., Smith G. P., Golden, D. M., Bowman, C. T., Hanson, R. K., Gardiner, W. C., and Lissianski, V., 1995, "GRI-Mech - An Optimized Detailed Chemical Reaction Mechanism for Methane Combustion", GRI Topical Report No. GRI-95/0058.

Green, R. M., Cernansky, N. P., Pitz, W. J., and Westbrook, C. K., 1987, "The Role of Low Temperature Chemistry in the Autoignition of n-Butane," SAE paper SAE-872108.

Heywood, John B., 1988, Internal Combustion Engine Fundamentals, McGraw-Hill, Inc., New York, NY.

Jensen, Scott P., 1994, “A Retrofit System to Convert a Locomotive to Natural Gas Operation," ASME, ICE-Vol 21, Natural Gas and Alternative Fuels for Engines, Book No. G00830. 
Lund, C. M., 1978 "HCT - A General Computer Program for Calculating Time-Dependent Phenomena Involving One-Dimensional Hydrodynamics, Transport, and Detailed Chemical Kinetics," Lawrence Livermore National Laboratory report UCRL-52504.

Najt, Paul M. and Foster, David E., 1983, “Compression-Ignited Homogeneous Charge Combustion," SAE paper 830264.

Pitz, W. J., Westbrook, C. K., and Leppard, W. R., 1991, “Autoignition Chemistry of C4 Olefins Under Motored Engine Conditions: A Comparison of Experimental and Modeling Results," SAE paper SAE-912315.

Ryan, Thomas W. III and Callahan, Timothy J., 1996 "Homogeneous Charge Compression Ignition of Diesel Fuel," SAE paper 961160.

Smith, J. R. and Aceves, S. M., 1996, "Preliminary Calculations on Homogeneous Diesel Combustion Concept," Summary report to US Department of Energy, Office of Transportation Technologies.

Theobald, M. A. and Henry, R., 1994, "Control of Engine Load Via Electromagnetic Valve Actuators," SAE paper 940816.

Westbrook, C. K., Pitz, W. J., and Leppard, W. R., 1991, “The Autoignition Chemistry of Paraffinic Fuels and Pro-Knock and Anti-Knock Additives: A Detailed Chemical Kinetic Study," SAE paper SAE-912314.

Westbrook, C. K., Warnatz, J., and Pitz, W. J., 1988, “A Detailed Chemical Kinetic Reaction Mechanism for the Oxidation of iso-Octane and n-Heptane over an Extended Temperature Range and its Application to Analysis of Engine Knock," Twenty-Second Symposium (International) on Combustion, p. 893, The Combustion Institute, Pittsburgh.

Woschni, G., 1967, "Universally Applicable Equation for the Instantaneous Heat Transfer Coefficient in the Internal Combustion Engine," SAE Paper 670931.

* Work performed under the auspices of the U.S. Department of Energy by the Lawrence Livermore National Laboratory under contract No. W-7405-Eng-48. 


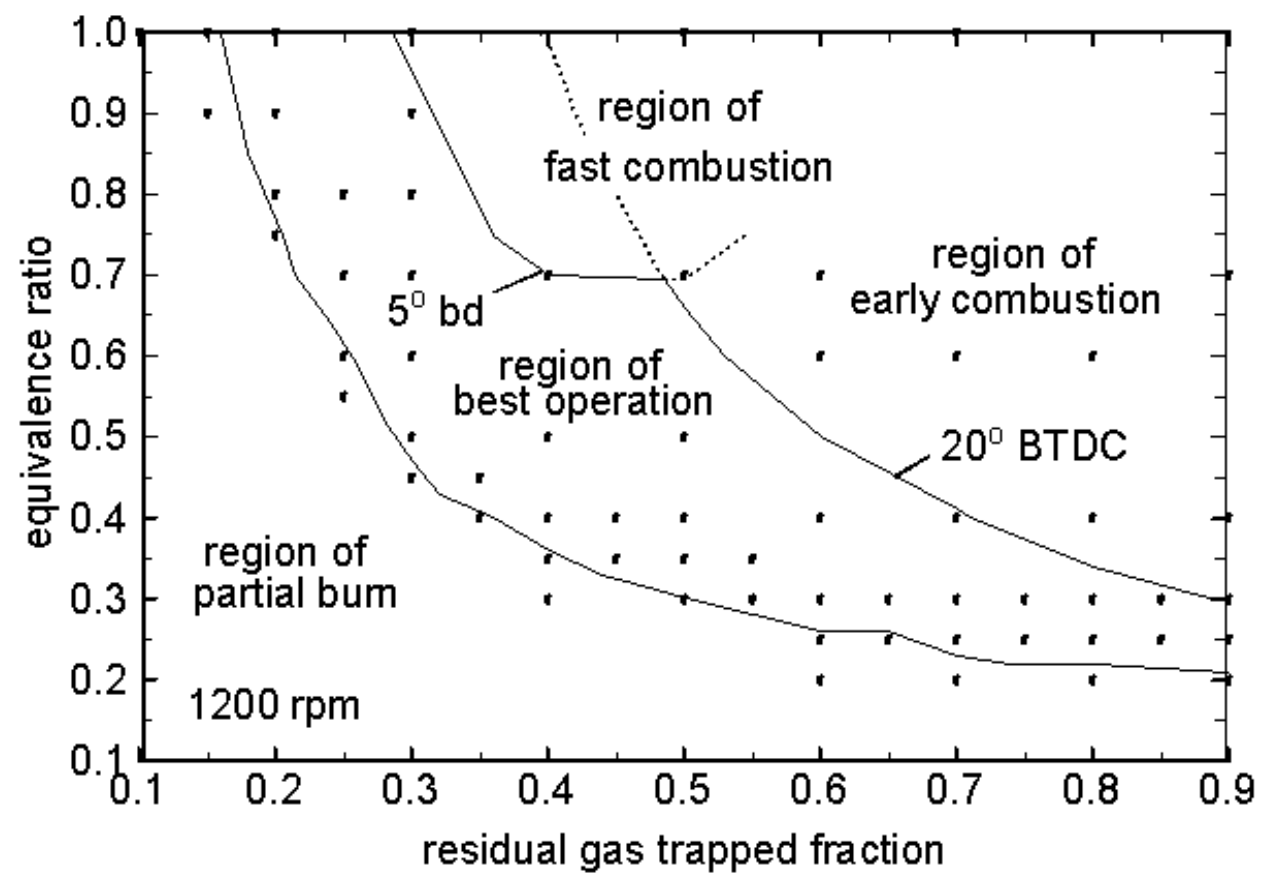

Figure 1 Methane HCCI regions of operation for $1200 \mathrm{rpm}, 15: 1$ compression ratio. Points indicate simulations done with HCT code. 


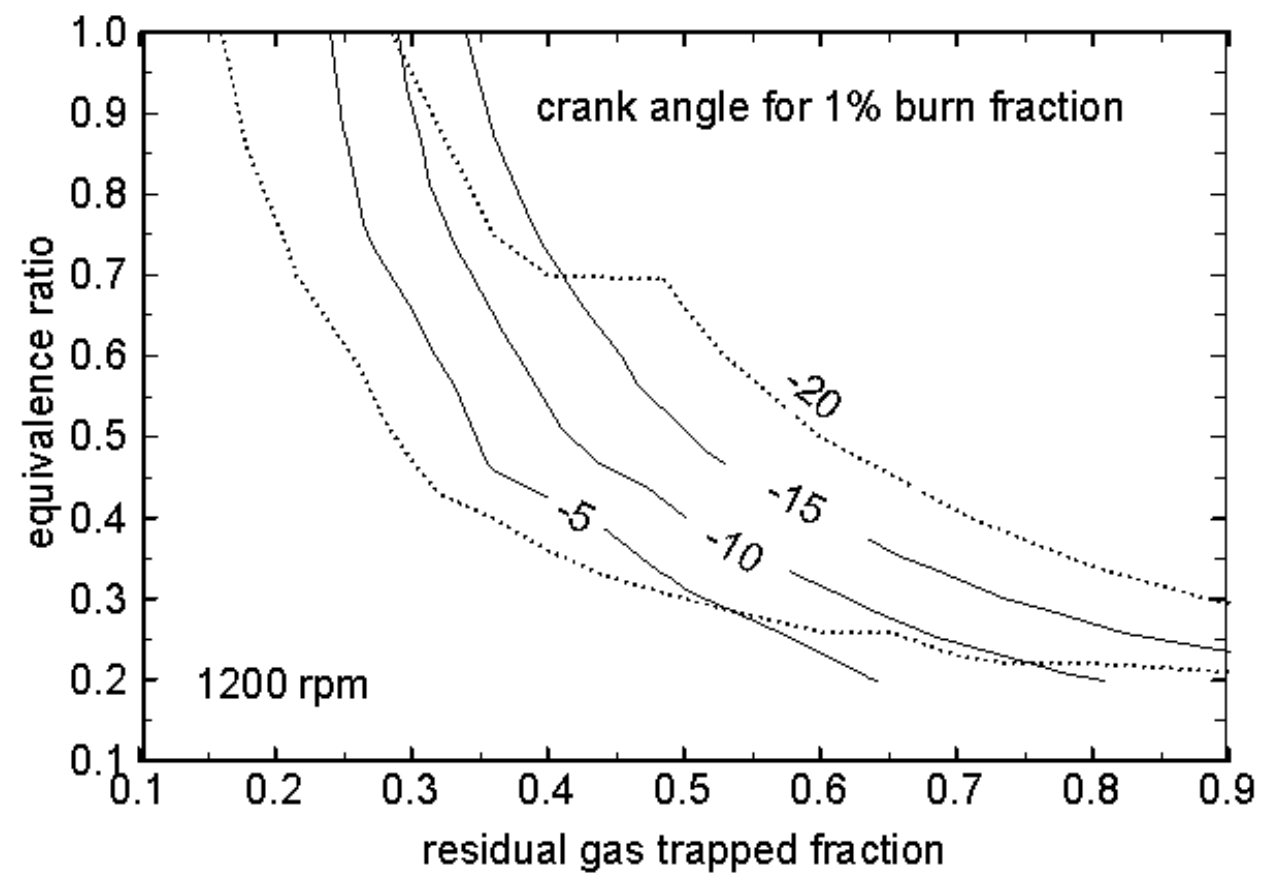

Figure 2 Contours one percent burn in crank angle degrees (negative is before TDC). 


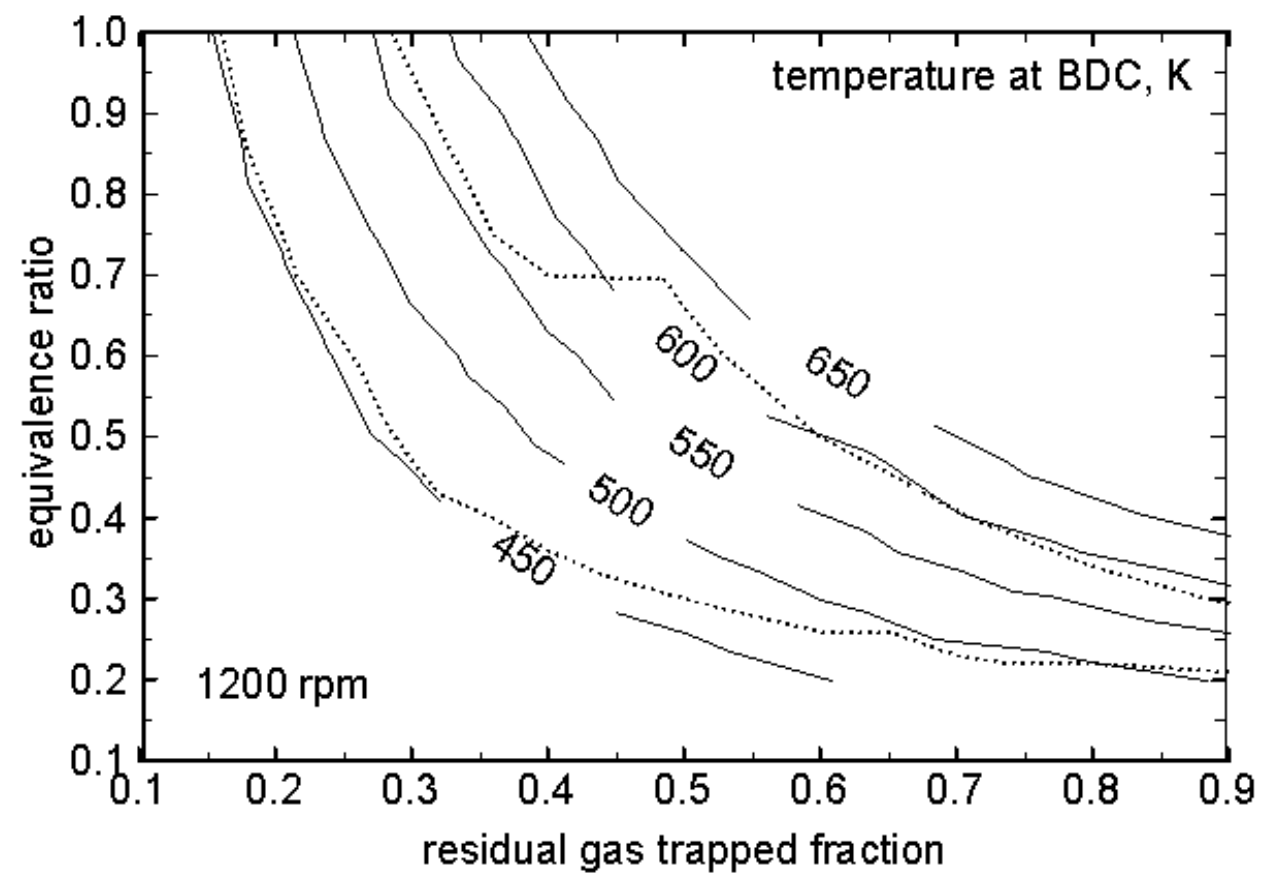

Figure 3 Temperature of charge at BDC in Kelvins. Inlet gas temperature is 330 Kelvin. Constant temperature contours align with $1 \%$ burn contour timing of Figure 2. 


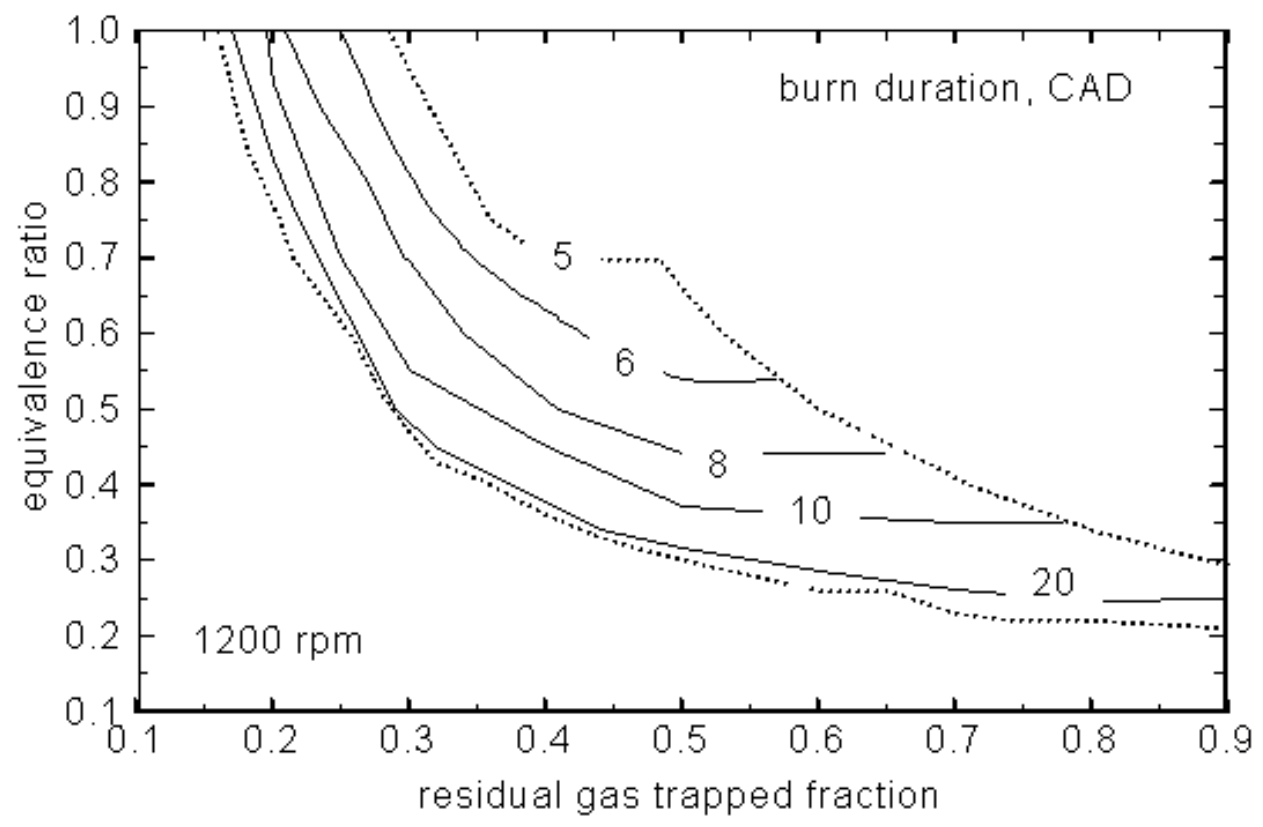

Figure 4 Burn duration (1\% to 99\%) in crank angle degrees in the region of best HCCI operation for $1200 \mathrm{rpm}$. 


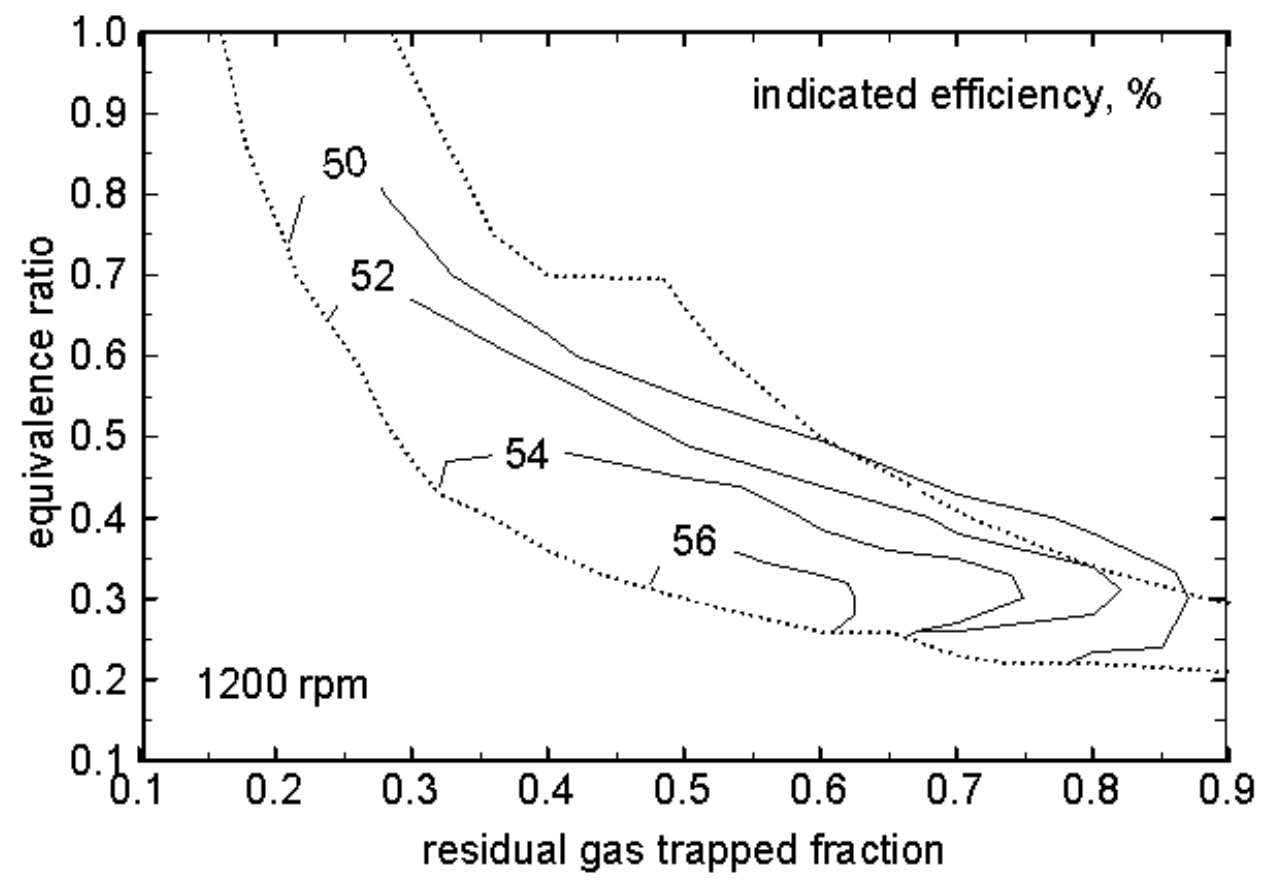

Figure 5 Indicated efficiency in the best region of operation at $1200 \mathrm{rpm}$. 


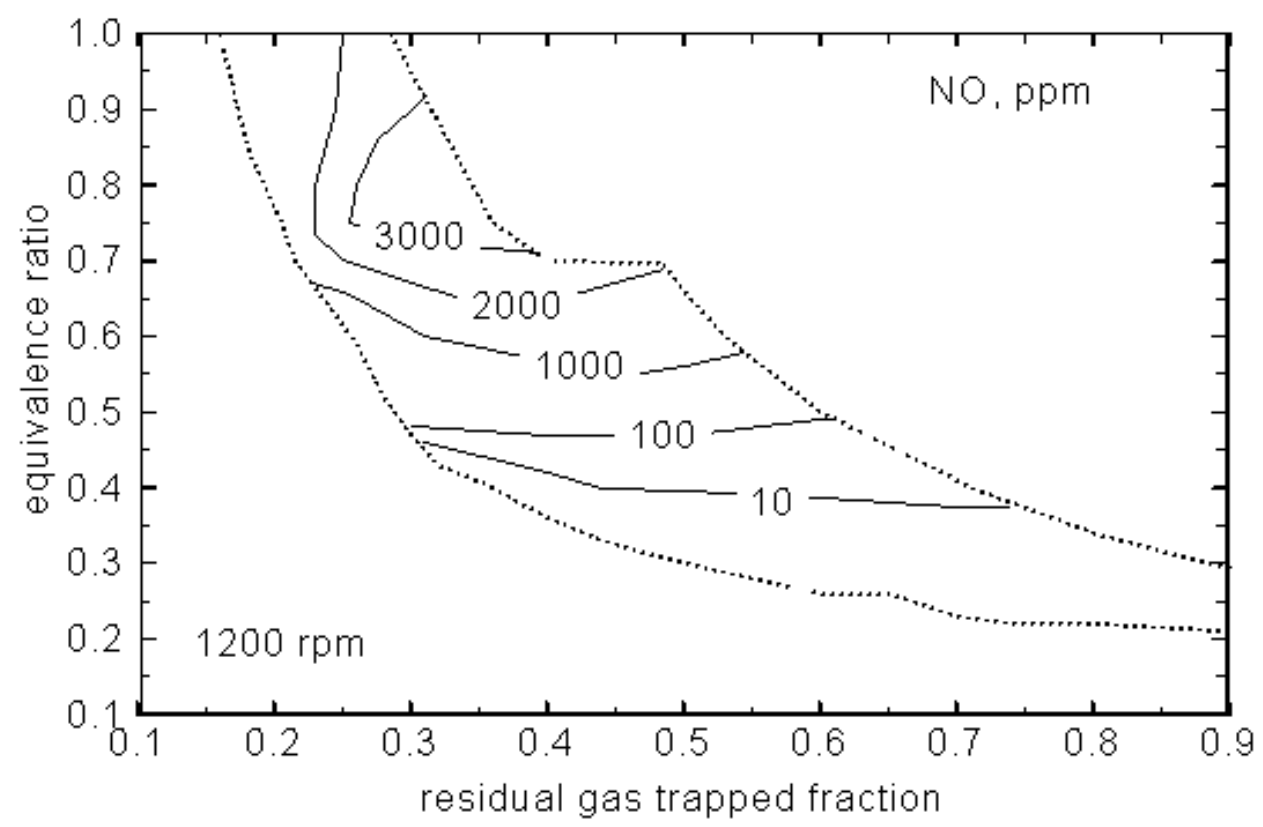

Figure 6 NO emissions in ppm in the region of best HCCI operation. NO represents over $98 \%$ of the total $\mathrm{NO}_{\mathrm{x}}$ emissions predicted. 


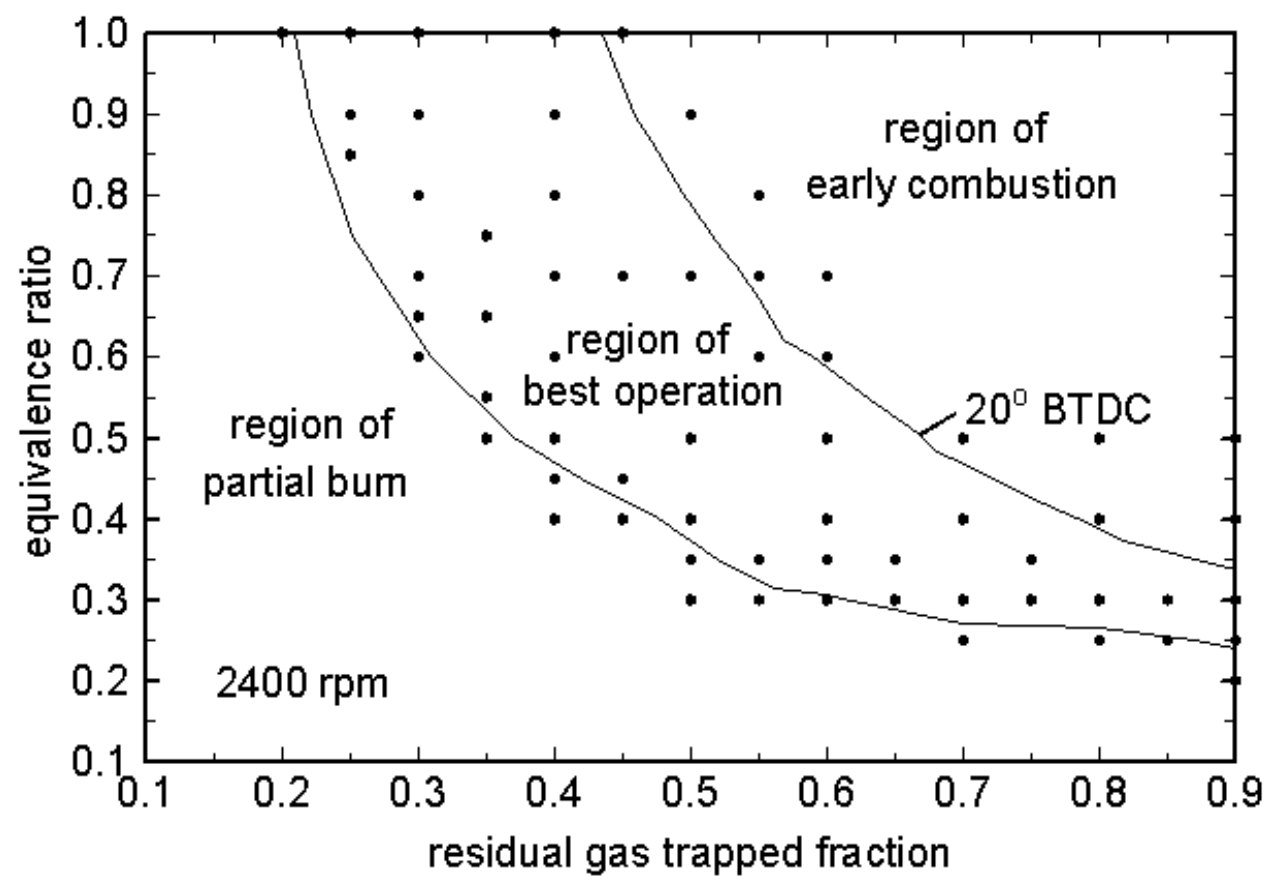

Figure 7 Methane HCCI regions of operation for $2400 \mathrm{rpm}$. Points indicate simulations done with HCT code. 


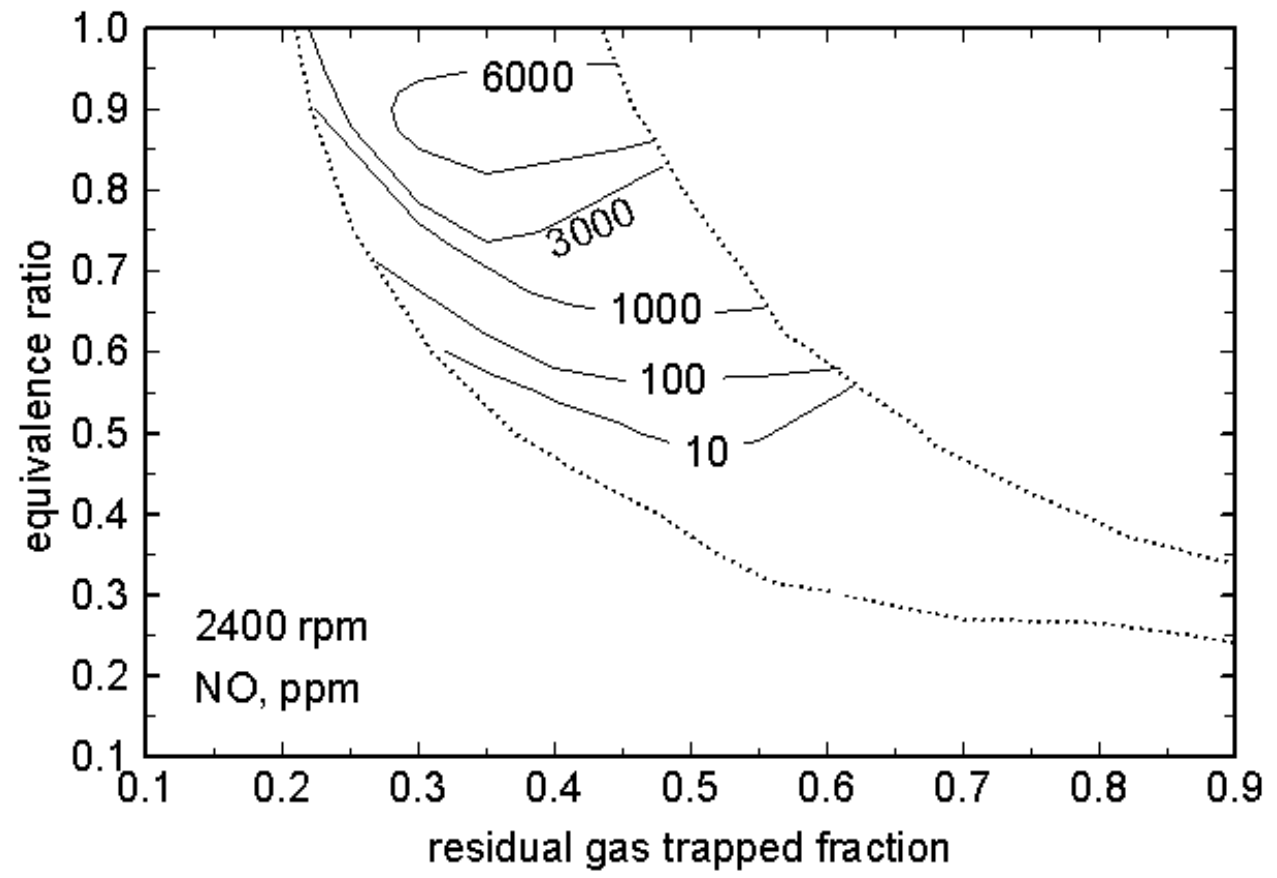

Figure 8 NO emissions in ppm in the region of best HCCI operation at $2400 \mathrm{rpm}$. 


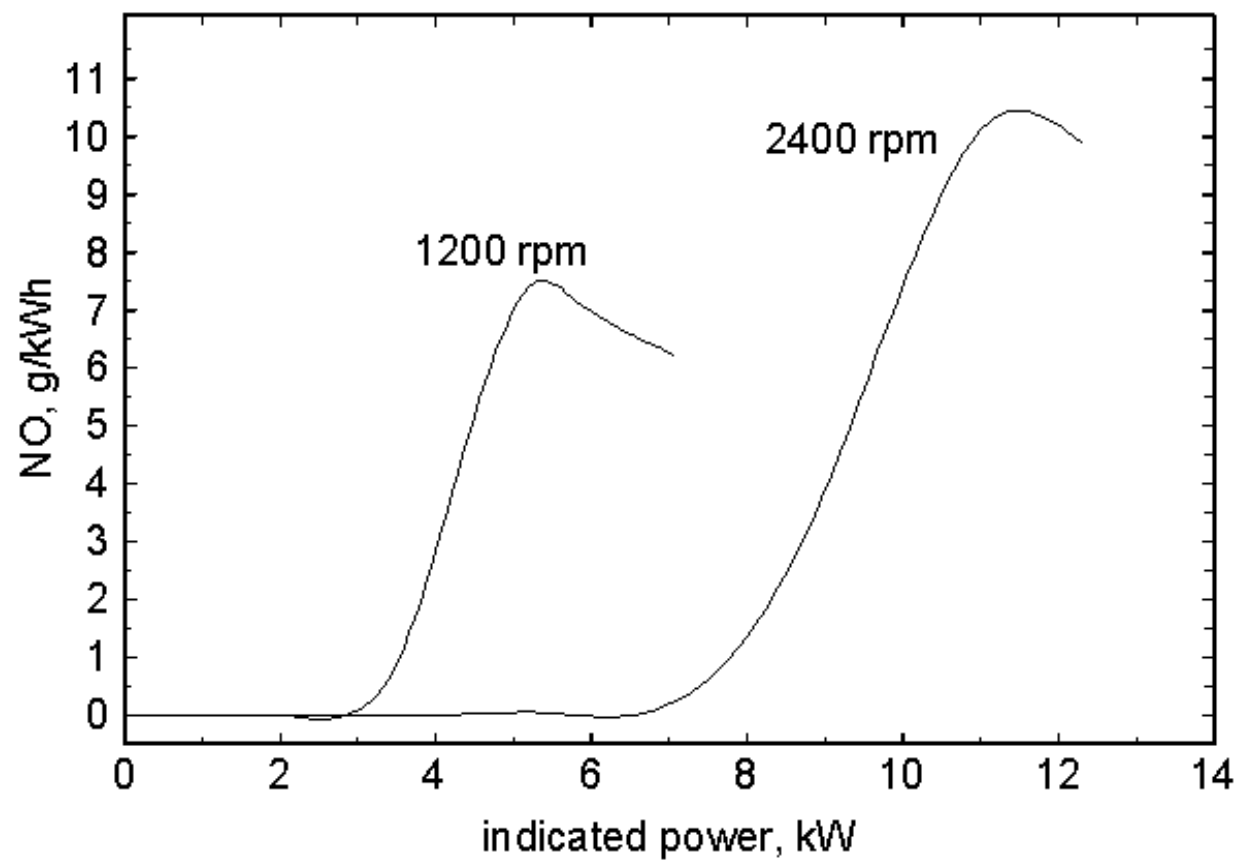

Figure 9 Specific NO in $\mathrm{g} / \mathrm{kWh}$ versus indicated power for 1200 and $2400 \mathrm{rpm}$.

Peak values occur at 0.9 equivalence ratio. Right hand end of curves are at stochiometric. 


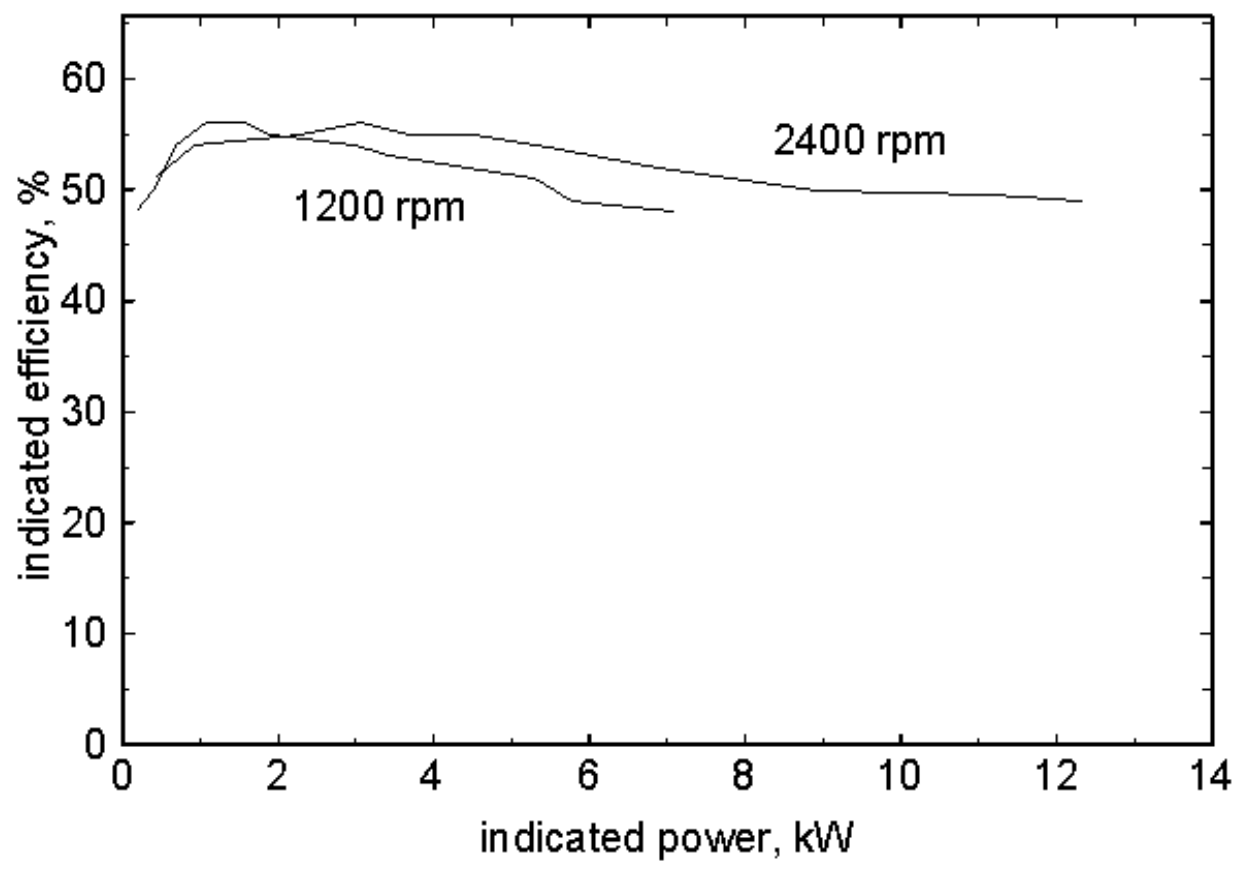

Figure 10 Indicated efficiency versus power for 1200 and $2400 \mathrm{rpm}$. 


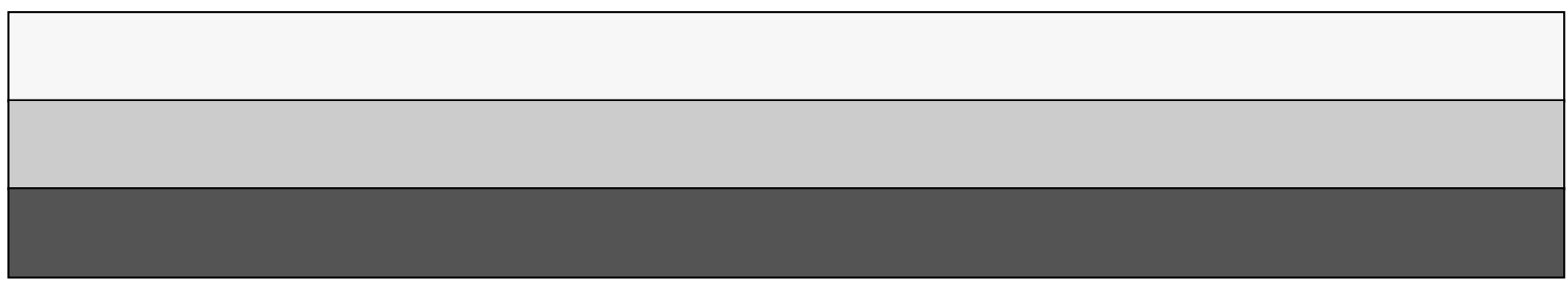

